\section{High-resolution mapping of forest vulnerability to wind 8 for disturbance-aware forestry}

\section{Authors and affiliations:}

Susanne Suvanto*1, Mikko Peltoniemi ${ }^{1}$, Sakari Tuominen ${ }^{1}$, Mikael Strandström ${ }^{1}$, Aleksi Lehtonen $^{1}$

${ }^{1}$ Natural Resources Institute Finland (Luke), Latokartanonkaari 9, 00790 Helsinki

*Corresponding author, susanne.suvanto@luke.fi

\section{Abstract}

Windstorms cause major disturbances in European forests. Forest management can play a key role in making forests more persistent to disturbances. However, better information is needed to support decision making that effectively accounts for wind disturbances. Here we show how empirical probability models of wind damage, combined with existing spatial data sets, can be used to provide fine-scale spatial information about disturbance probability over large areas. First, we created stand-level damage probability models using wind damage observations within 5-year time window in national forest inventory data (NFI). Model predictors described forest characteristics, forest management history, 10-year return-rate of maximum wind speed, and soil, site and climate conditions. We tested three different methods for creating the damage probability models - generalized linear models $\left(G L M^{1}\right)$,

\footnotetext{
${ }_{1}^{1}$ Abbreviations: AUC - area under curve, BRT - boosted regression trees, dd - degree days, GAM generalized additive model, GAMM - generalized additive mixed model, GIS - geographic information system, GLM - generalized linear model, GLMM - generalized linear mixed model, GTK - Geological Survey of Finland, GVIF - generalized variance inflation factor, MS-NFI - multi-source national forest inventory, NFI (NFI11, NFI12)
} 
generalized additive models (GAM) and boosted regression trees (BRT). Then, damage probability maps were calculated by combining the models with GIS data sets representing the model predictors. Finally, we demonstrated the predictive performance of the damage probability maps with a large, independent test data of over 33,000 NFI plots, which shows that the maps are able to identify vulnerable forests also in new wind damage events, with area under curve value $(A \cup C)>0.7$. Use of the more complex methods (GAM and BRT) was not found to improve the performance of the map compared to GLM, and therefore we prefer using the simpler GLM method that can be more easily interpreted. The map allows identification of vulnerable forest areas in high spatial resolution (16 m x $16 \mathrm{~m}$ ), making it useful in assessing the vulnerability of individual forest stands when making management decisions. The map is also a powerful tool for communicating disturbance risks to forest owners and managers and it has the potential to steer forest management practices to a more disturbance-aware direction. Our study showed that in spite of the inherent stochasticity of the wind and damage phenomena at all spatial scales, it can be modelled with good accuracy across large spatial scales when existing ground and earth observation data sources are combined smartly. With improving data quality and availability, map-based risk assessments can be extended to other regions and other disturbance types.

44 Keywords: forest disturbances; storm damage; windthrow; tree mortality; forest management

\section{Introduction}

47 Forest wind disturbances have major economic, societal and ecological consequences in 48 Europe. Forest disturbances have substantial effects on forest productivity and carbon storage (Seidl et al., 2014; Reyer et al., 2017). In European forests, the disturbance-related reduction of the carbon storage potential has been estimated to be $503.4 \mathrm{Tg} \mathrm{C}$ in years

- national forest inventory (11th Finnish NFI, 12th Finnish NFI), NLS - National Land Survey of Finland, RFrandom forest, $\mathrm{ROC}$ - receiver operating characteristic 
2021-2030 (Seidl et al., 2014). Actions to reduce and manage the disturbances are thus crucial in assuring the persistence of the forest carbon sinks. The damage caused by wind storms in European forests has increased during the past century (Schelhaas et al., 2003; Seidl et al., 2011, Gregow et al., 2017) and this trend is expected to continue (Ikonen et al., 2017; Seidl et al., 2017). The question of forest wind disturbances is therefore becoming increasingly important in the future.

Forest management practices play a key role in making forests less vulnerable to wind disturbances. Management driven changes in European forests, such as increasing standing timber volume and promotion of conifer species, have been identified as one of the major causes of increased forest disturbances in Europe during the latter half of the 20th century (Schelhaas et al., 2003; Seidl et al., 2011). If management practices are shifted to reduce forest vulnerability to wind, it may be possible to decrease the negative effects of wind disturbances. However, changing the forest management practises to more disturbanceaware direction is not always easy, as illustrated by the 2005 storm Gudrun in southern Sweden: despite the massive damage and economic losses caused by the storm and the Swedish Forest Agency's recommendations for alternative, less vulnerable, management options, the forest management practises in the area remained largely unchanged after the storm (Valinger et al., 2014, Andersson et al., 2018). This demonstrates that not only is information about the wind damage risks urgently needed to account for disturbances in management decisions, but it is also crucial that this information is in a form that can be effectively used and communicated to forest owners and managers.

The development of remote sensing methods and the progress of open data policies have substantially increased the amount, quality and availability of spatial data relating to forests. This opens new possibilities for detailed spatial estimation of forest sensitivity to disturbances. Vulnerability of forests to wind damage is affected by forest characteristics, forest management as well as the abiotic environment, such as local wind and soil conditions (Mitchell, 2013). For example, probability of wind damage has been shown to 
increase with tree height and certain species, such as Norway spruce, are particularly vulnerable to wind (Peltola et al., 1999; Dobbertin, 2002; Valinger and Fridman, 2011). Forest management has major effects on wind damage sensitivity, as trees that have grown in sheltered conditions and have later been exposed to wind, because of thinning or clear cut of the neighboring stand, are especially sensitive to damage (Lohmander and Helles, 1987; Peltola et al., 1999; Suvanto et al., 2016). Areas that are exposed to strong wind gusts (Schindler et al., 2016) or where rooting conditions are limited due to soil characteristics (Nicoll et al., 2006) are more predisposed to wind damage. Therefore, in order to provide useful information on forest vulnerability to wind, information from several different sources, scales and disciplines needs to be brought together.

Logistic generalized linear models (GLM) have long been applied in statistical modelling of forest wind damage (Lohmander and Helles, 1987; Valinger and Fridman, 1997; Suvanto et al., 2016). In addition, different approaches allowing more flexible model behaviour than fully parametric GLMs have been used, such as generalized additive models (GAM; Schmidt et al., 2010) that use non-parametric smooth functions to allow more flexibility in the relationship of response variable and predictors (Hastie et al., 2009). Machine learning approaches have also been successfully applied to wind disturbance modeling (see Hanewinkel et al. 2004 for an early example) and recently especially tree-based ensemble models, such as random forests (RF) and boosted regression trees (BRT), have been popular and often shown to perform well in predicting wind damage (see Schindler et al., 2016; Kabir et al., 2018; Albrecht et al., 2019; Hart et al., 2019 for examples using RF and Díaz-Yáñez et al. 2019 for BRT). While machine learning methods and additive models are able to more flexibly fit the data and account for non-linearities, GLMs have strengths in their straightforward interpretability and the robustness of predictions (Nakou et al., 2016; Albrecht et al., 2019).

In this study, our goal was to answer the need for information to be used for taking forest disturbances into account in management decisions by creating a high-resolution map of 
105 forest vulnerability to wind damage, using damage observations from national forest 106 inventory (NFI) data. While there have been some previous attempts to map forest 107 vulnerability to wind damage using statistical models (Schindler et al., 2009; Saarinen et al., 108 2016; Suvanto et al., 2016), the resulting maps and their applicability to disturbance 109 situations outside of the original model data have rarely been rigorously tested, limiting the 110 conclusions that can be drawn about the performance and usefulness of such maps. In 111 addition, we aimed to test the suitability of different modelling methods, ranging from fully-

112 parametric GLM to more flexible methods, for creating such maps. More specifically, our 113 aims were to (1) create a damage probability statistical model based on a large and 114 representative data set of wind damage observations in the Finnish NFI, (2) compare three 115 methods for creating the model, GLM, GAM and BRT, to test the suitability of different 116 methods for the task, (3) calculate a damage probability maps by combining the models with 117 national extent GIS layers of model predictors, compiled from different sources, and (4) test 118 the performance of the maps with a large data set containing independent damage 119 observations from over 33,000 NFI plots.

\section{2. Material and methods}

\subsection{National Forest Inventory and wind damage observations}

122 In this study, we used stand level wind damage observations from the $11^{\text {th }}$ Finnish national forest inventory (NFI11) to create an empirical model of wind damage probability (Fig. 1).

124 The field work for the NFI11 was conducted from 2009 to 2013 (Korhonen, 2016; Korhonen et al., 2017). In later stages of the study, we also used NFI12 (field work in 2014 to 2018) to test the created map (see section 2.5).

127 In our analysis, we only included plots that were defined as forest land. Poorly productive

128 forests were excluded because they are unimportant for forestry and their wind damage risks 129 tend to be small due to low volume of growing stock. In addition, plots on treeless stands or 130 seedling stands without upper canopy layer were excluded because seedlings have very low 
wind damage probability (8633 plots). Plots with missing data or unrealistic (erroneous)

132 values for any of the used variables were excluded (52 plots). Plots within less than $1 \mathrm{~km}$ 133 from the national border were also excluded, as the data set describing local wind conditions 134 (Venäläinen et al., 2017) had edge effects (214 plots). If a plot was located on the border of 135 two or more forest stands, we only used the data from the stand where the plot centre was 136 located. The final data set consisted of a total of $41,392 \mathrm{NFI}$ plots.

137 Observations of stand level wind damage and an estimate of the damage time is documented in the Finnish NFI (Tomppo et al., 2011; Korhonen, 2016). Here, we used only the wind damage observations that had occurred no more than 5 years before the date of the field visit. Since the field work of NFI11 was done in 2009 to 2013, the data can contain observations from damage that has occurred between 2004 and 2013. During these years,

142 several high impact storms affected Finland, such as cyclone Dagmar (known as Tapani in 143 Finland), which caused severe damage in Finland during December $26^{\text {th }}$ and $27^{\text {th }} 2011$ 144 (Kufeoglu and Lehtonen 2014), and a series of severe thunderstorms in summer 2010 (Viiri 145 et al. 2010).

146 The severity of damage was not considered in the analysis, because the degree of damage 147 was only recorded as cumulative effect of all damage agents, and no information of wind 148 damage severity was available in cases where there was more than one damaging agent 149 present. The restriction of the analysis to only severe damage cases would also have limited 150 the number of damage observations available. Therefore, the binary damage variable 151 contains stands with different damage severities. Stand level wind damage was observed at 1521,070 plots of the total $41,392 \mathrm{NFI}$ plots in the dataset.

\subsection{Model predictors}

\section{$154 \quad 2.2 .1$ National Forest Inventory data}

155 Most predictors in the statistical models were extracted from the NFI field data (Tables 1-2).

156 To describe the forest characteristics of the stand, dominant tree species and mean tree 
157 height in the stand were used. If several canopy layers and species were recorded in the 158 data, the values from the layer with largest tree height were used, as the tallest trees can be 159 assumed to be most vulnerable to wind. The NFI also documents the type and time of most recent forest management operations, and based on this data we created a variable describing the time since last thinning.

162 NFI information about soil type, soil depth and site fertility was also used (Tables 1-2). Soil 163 type variable differentiated between organic and mineral soils, as well as fine and coarse 164 grained mineral soils. Fine mineral soils included clay and fine sands, whereas sands and 165 coarser soils were classified as coarse mineral soils. Grain size was estimated on the field by NFI teams. Site fertility classes in the NFI are estimated in eight classes, but in our analysis they were regrouped into two classes so that class "Fertile" contained sites from herb-rich to mesic forests on mineral soils and from euthrophic to meso-oligothrophic peatlands. Less fertile classes were included in the "Poor" fertility class (see Tomppo et al., 2011 for detailed description of the site fertility classes used in the Finnish NFI).

171 The used data covers the whole country and contains damage observations from several 172 years and, there is thus large variation in the wind conditions experienced by the trees in the 173 data. Not all plots were exposed to similar wind conditions and this needed to be taken into account in the statistical model. However, we did not have reliable data available about the spatial variation in maximum wind speed conditions during the study period and lacking such an important factor affecting the damage probability is likely to bias the estimation of the effects of other predictors. Therefore, a different approach was taken. To account for areas subjected to severe storm events, variable "Damage density ratio" was calculated using the locations of NFI plots as the ratio of 2D kernel density of damaged plots and all plots (Table 1). That is, the ratio describes the spatial density of damaged plots in comparison to all NFI plots included in the model. A value of 2, for example, can therefore be interpreted as two times higher density of damaged plots than what would be expected from the density of all plots. The damage density variable was then transformed into a categorical variable (with 
classes $0-2,2-3$, and $>3$ ). The upper limit of the lowest class was set relatively high to identify only the strongest clusters of damaged plots and to avoid catching all the large-scale spatial trends with this variable. The calculations were done in $\mathrm{R}$ with the KernSmooth package (Wand, 2015) using bandwidth of $20 \mathrm{~km}$ (see details in S1).

\subsubsection{Other data sets and the delineation of forest stands}

In addition to the NFI field data we also supplemented the model predictor set with additional variables describing local wind conditions and open forest borders from other data sources (Tables 1-2). To describe the long-term wind conditions at each plot, we used a data set describing the local 10-year return levels of maximum wind speeds in $20 \mathrm{~m} \times 20 \mathrm{~m}$ raster cells. That is, the value of each pixel represents the level of maximum wind speed $\left(\mathrm{ms}^{-1}\right)$ expected to be reached on average once in every 10 years (detailed description of the data and its methodology in Venäläinen et al., 2017; see S5 for map of the data). The data is downscaled from coarse-scale wind speed estimates in ERA-Interim reanalyzed data with a wind multiplier approach using CORINE land-use data and digital elevation model (Venäläinen et al., 2017). The data set contains maximum wind speeds calculated for eight different wind directions, and in this study we used the maximum value of these for each pixel.

To identify stands with open forest borders (variable 'Open neighbour stand', Table 1), we used the multi-source NFI forest resource maps (MS-NFI; Tomppo et al., 2008; Mäkisara et al., 2016) that combine satellite data and NFI field data to create national extent forest resource maps in a $16 \mathrm{~m} \times 16 \mathrm{~m}$ resolution grid.

However, the used wind damage observations were documented on the level of forest stands and the stand borders were not mapped in the data but only estimated by the NFI team at the field. Therefore, in order to combine the stand-level damage information with other data sources, the locations of stand borders first needed to be defined. A forest stand in the the Finnish NFI is defined as spatially continuous land area that is homogeneous with 
210 respect to properties such as administrative boundaries, site fertility, structure of the growing

211 stock (e.g. maturity class, tree species composition) and forest management (Tomppo et al.,

212 2011). To create polygons that would approximately correspond to the stands assessed in

213 the field by the NFI team, we used image segmentation on the MS-NFI data layers

214 (corresponding to year 2013) describing growing stock volumes by main tree species groups

215 (pine, spruce and deciduous species) and tree height. Land property boundaries obtained

216 from the National Land Survey of Finland were also included in the segmentation, as they

217 are considered as stand boundaries in the NFI. The image segmentation was conducted

218 with the methodology described by Pekkarinen (2002), using the "segmentation by directed

219 trees" algorithm by Narendra and Goldberg (1980).

220 Once the stand polygons were defined with image segmentation, they were used for 221 calculating local wind conditions and finding stands with open stand borders. For each stand 222 polygon, maximum wind-speed within the stand boundaries was calculated (Table 1). 223 Maximum value was used because the NFI field data does not specify the exact location of 224 the damage within the stand, and we assumed that damage occurred in the most wind 225 exposed part of the stand.

226 To identify plots with open neighbor stands, median tree height was first calculated for each 227 stand polygon using the MS-NFI tree height data. A stand was defined to have an open 228 stand neighbor if the median tree height of any of the stand neighbours was smaller than 5 229 meters (Table 1). Median was used instead of mean so that it would be less affected by 230 possible outlier values resulting from inaccuracies in defining the stand polygons.

231 Calculations of maximum wind speeds and open stand neighbors for the segments were 232 conducted with PostGIS (version 2.4.0) and Python (version 2.7.12) with packages 233 geopandas (version 0.3.0) and rasterstats (version 0.12.0). 
235 Damage probability models were created using three different methods: GLM, GAM (Wood 236 2006) and BRT (Elith et al., 2008). In all the models the dependent variable was the 237 presence of wind damage in the stand and independent variables described forest characteristics, forest management history, soil and site type, the 10-year return level of maximum wind speed, temperature sum and the local damage density ratio (Table 1).

240 Binomial GLM with logit-link function were fitted in R (version 3.5.1, R Core Team, 2017). To 241 account for non-linear relationships, logarithm transformation were tested for all continuous 242 independent variables and included in the final model if they showed lower AIC than models 243 with non-transformed variables. The transformations were included only for the GLM model, since GAM and BRT enable more flexibility in the shapes of the relationship between 245 response variable and predictors, and can therefore account for non-linear relationships 246 without transformations.

247 Variable selection was based on several criteria: (1) only variables that, based on earlier 248 research, were expected to have a causal effect to wind damage probability were included, 249 (2) since the ultimate goal of the model was to produce the damage probability map, we only 250 included variables for which reasonably high-quality national-extent GIS data sets were 251 available or could be derived from existing data, (3) the behaviour of the variable in the 252 model was plausible based on existing understanding of forest wind damage. We also aimed 253 to build the model so that all major components related to wind damage probability were included. Collinearity of predictors was inspected with Pearson's correlation coefficients and 255 generalized variance inflation factors (GVIF, Fox and Monette, 1992). All correlations 256 between included continuous predictor variables were weaker than 0.5 and GVIFs for all 257 variables were lower than 4.

258 GAM is an extension of a GLM where the linear predictor contains a sum of smooth 259 functions of covariates. This specification of the model in terms of smooth functions instead 260 of detailed parametric relationships allows for more flexibility in the dependence of the 
response of the covariates (Wood, 2017). In our analysis, GAM with logit-link function was

262 fitted in R with package mgcv (version 1.8-24, Wood, 2011), using the same predictors that were included in the GLM. All continuous predictors were included in the model through nonlinear smoothing spline functions. The dimension parameter $(k)$, effectively setting the upper limit on the degrees of freedom related to the smooth, was set to 15 for all variables, except for temperature sum for which $k=5$ was chosen to avoid unrealistically fluctuating largescale patterns in the predictions. The effective degrees of freedom (edf) after fitting the model were lower than $\mathrm{k}$ for all of the terms (see $\mathrm{S} 2$ for details), suggesting that the chosen k's were sufficiently large.

BRT is an ensemble method that combines a large number of regression trees with a boosting algorithm (Elith et al., 2008). Here, BRTs were computed with R package dismo 272 (version 1.1-4, Hijmans et al., 2017). To find the best parameters, BRTs with different parameter combinations of tree complexity (tested values $1,2,3$ and 5$)$, learning rate $(0.05$, 0.01 and 0.005$)$ and bag fraction $(0.5,0.6$ and 0.75$)$ were fitted. The number of trees was not assigned manually, but was estimated with k-fold cross-validation using the function gbm.step (Hijmans et al., 2017). To estimate the number of trees and to compare different parameter combinations, gbm.step was run separately for each parameter combination.

278 Following the rule-of-thumb suggested by Elith et al. (2008), we excluded parameter 279 combinations that led to models with fewer than 1000 trees. Thus, the model with parameter combination leading to lowest holdout residual deviance in the cross-validation performed by gbm.step and at least 1,000 trees was chosen for the final model (tree complexity $=2$, learning rate $=0.01$, bag fraction $=0.5,2,250$ trees, see S3 for details).

To make sure that the unbalanced ratio of damaged versus non-damaged plots did not affect the results, BRTs were fitted also from two balanced datasets where the balancing of the observations was done by (1) undersampling the non-damaged plots or (2) oversampling the damaged plots. In both cases the cross-validated area under curve (AUC) values were very 
similar to ones calculated from the original unbalanced dataset and, therefore, the original data set was used for the final results.

To account for the sampling design, weights based on the forest area each plot represents were used in all models (Korhonen, 2016). For example, in northern Finland the NFI sampling design is sparser and therefore the weight of one plot in modelling is higher. To test if the clustered sampling design had an effect on the results, GLMs and GAMs were also fitted as mixed models (GLMM and GAMM) with plot clusters as random intercepts, using $\mathrm{R}$ packages Ime4 (Bates et al., 2015) for GLMM and gamm4 (Wood and Scheipl, 2017) for GAMM. However, as the mixed model predictions (in the scale of the linear predictor, using only fixed effects for prediction) were highly correlated with the fixed effect model prediction (Pearson's $r=0.998, p<0.001$ for GLM vs GLMM, and $r=0.979, p<0.001$ for GAM vs GAMM) and our interest was in marginal instead of conditional inference, no random effects were included in the final models.

The models were validated with 10 -fold stratified cross-validation, where number of damaged plots was divided evenly into the folds. In the cross-validation, the variation in damage density variable was not used in the prediction, because the variable was included in the model only to account for spatial structures in storm severity in the data, and in an aimed use case of the models (i.e., estimating damage vulnerability in future events) we would not have this information available. Instead, separate predictions for test-folds were calculated with each class of the damage density variable $(0-2,2-3,>3)$. Then, these three predictions were averaged based on the frequency of each class in the original model data.

\section{See details in S1.}

Receiver operating characteristic (ROC) curves and AUC values were calculated for each

310 iteration of cross-validation and used to assess the performance of the models. The ROC

311 curve plots the true positive rate (sensitivity) and true negative rate (specificity) of the model 312 with all possible classification thresholds. The AUC values represent the area under ROC 
curve and measure the model's ability to discriminate between events and non-events. AUC

314 values of 0.5 correspond to a situation where the classifier is no better than random (ROC 315 curve along diagonal) and value of 1 a situation where the model perfectly discriminates 316 between events and non-events. As a rule of thumb, AUC values over 0.7 are considered 317 acceptable discrimination between classes, values over 0.8 excellent and values over 0.9 outstanding (Hosmer et al., 2013).

\subsection{Calculation of the damage probability map}

320 A GIS raster data layer with resolution of $16 \mathrm{~m} \times 16 \mathrm{~m}$ and extent of the whole country was prepared for each predictor variable used in the models (Table 1). Forest variables (dominant species, tree height, height-diameter ratio, open forest edge) were derived from the Finnish MS-NFI data for year 2015 (Mäkisara et al., 2019). A grid cell was defined to be on an open forest edge if tree height in the MS-NFI data was lower than 5 meters in any of the cells within a $5 \times 5$ cell neighborhood.

Spatial data on forest management history (the time of last thinning) was derived from the forest use notification collected by the Finnish Forest Centre. This data consists of forest use notifications that forest owners are required to report to the Forest Centre before conducting management operations in their forests. For each $16 \mathrm{~m} \times 16 \mathrm{~m}$ pixel, we first assigned the year of the latest notification of planned thinning in that location of the pixel and then calculated the difference to year 2015 .

332 Data for the 10-year return-rates of maximum wind (Venäläinen et al., 2017), originally in 20 $333 \mathrm{~m} \times 20 \mathrm{~m}$ resolution, was resampled to the $16 \mathrm{~m} \times 16 \mathrm{~m}$ grid with GDAL using bilinear 334 interpolation. Soil type was defined as ORGANIC for areas within the peatland polygons in 335 the Topographic Database produced by the National Land Survey of Finland (NLS, 2018). 336 Other areas were defined as mineral soils, and further divided to fine or coarse mineral soils based on the top soil information in the 1:200,000 resolution soil map of the Geological

338 Survey of Finland (GTK, 2018). Data layer for soil fertility classes was made by reclassifying 
339 the MS-NFI fertility class data layer from the original five classes to the two classes used in

340 the models (see details in section 2.2.1). Average annual temperature sum was calculated 341 with a threshold of $5^{\circ} \mathrm{C}$ from daily weather data grids (Aalto et al., 2016) for the years 1985 342 to 2014.

343 Similarly as in the cross-validation, the variation in damage density variable was not used in

344 the prediction, because we would not have this information available for future events. 345 Instead, separate predictions were calculated with each class of the damage density variable 346 and these three predictions were then averaged based on the frequency of each class in the 347 original model data. See details in S1.

348 The damage probability map was calculated from the GLM, GAM and BRT model objects 349 and the GIS data layers using $R$ packages raster (Hijmans, 2017) and sp (Pebesma and 350 Bivand, 2005).

\subsection{Testing the map with new damage observations}

352 The accuracy of the damage probability map was validated with an independent test data 353 set. The map was compared to the damage observations in the most recent NFI 354 measurements $\left(12^{\text {th }}\right.$ Finnish NFI, NFI12), which were not included in the model fitting data 355 that was from the NFI11. Compared to NFI11, which covers the whole country, NFI12 does 356 not cover the northernmost parts of Finland as plots in the three most northern municipalities 357 (Northern Lapland), where the proportion of forest land is low, are not measured as 358 frequently as other parts of the country (see S5 for maps of plot locations in NFI11 and $359 \mathrm{NFI}$ 12).

360 We included the NFI12 plots that had been measured during 2014-2018, were classified as

361 forest land by the field team, and were located within forest area in the MS-NFI forest 362 resource maps (i.e., there were data in the wind damage probability map at the location of 363 the plot). For wind damage we also used the same criteria as with the model data, i.e. only 364 observations estimated to have occurred during the last 5 years were included and the 
severity of the damage was not considered. In addition, those permanent plots that were measured already in NFI11 were excluded from the test data, as the previous measurements in the same plots were used in the model fitting. The final test data consisted of 33,754 plots with wind damage in 734 of the plots.

369

Values of the wind damage probability maps were extracted at the locations of test data plots as the mean value of map pixels within 20 meter buffer from the location of the plot center. ROC curves and AUC values were calculated using the wind damage information in the test data and the extracted values of the damage probability maps. The extraction was conducted in $\mathrm{R}$ with package raster (version 2.8-19, Hijmans, 2017) and ROC/AUC calculations with package $p R O C$ (version 1.12.1, Robin et al., 2011).

\section{Results}

The results showed that forest vulnerability to wind damage is strongly driven by forest characteristics, especially tree height. In all models, the damage probability increased with tree height, and the increase was strongest for spruce dominated forests (see Fig. 2 and Table 3 for GLM, Fig. 3 for GAM and Fig. 4 for BRT). Higher values of damage density ratio led to higher damage probability in all models, as expected (Fig. 5). Also forest management affected damage probability in the models, as recently thinned forests and forests with open stand borders were more susceptible to damage. These predictors, related to the forest characteristics, very much drive the fine-scale spatial variation of damage probability in the (Fig. 7).

Wind damage probability was found to show distinct large-scale trends, most importantly the decreasing damage probability from south to north (Fig. 7). This effect in the models comes from the temperature sum, but also other predictors contributed to the large-scale trends in the map, as there as large-scale patterns in wind conditions, forest characteristics and soil and site fertility conditions (see Fig. 2 for GLM, Fig. 3 for GAM and Fig. 4 for BRT, S5 for maps of predictor raster data). The north-south pattern in damage density was evident in the 
damage probability maps with all model methods. However, the map created with the BRT

392 showed unexpectedly high damage probability values for the northernmost parts of the 393 country (Fig. 7).

394 The model predictors showed in general rather similar effects in the three tested methods

395 (GLM, GAM and BRT). Yet, there are also differences, especially in the shape of relationship 396 between the continuous predictors and predicted damage probability. In GLM, the 397 relationships are restricted to sigmoidal curves (Fig. 2), whereas GAM (Fig. 3) and BRT (Fig. 398 4) allow more flexible shapes of responses. This can be seen, for example, in how 399 increasing tree height in pine forests shows steadily increasing damage probability with GLM 400 (Fig. 2) whereas in GAM damage probability peaks around tree height $200 \mathrm{dm}$ and then 401 declines (Fig. 3).

402 As the BRT predictions are calculated from ensembles of regression trees, they enable very 403 sharp changes in the prediction within small changes in the values of the predictor (Fig. 4).

404 They can also contain diverse interactions between the predictors, which are unfortunately 405 not visible in partial dependence plots like Fig. 4. The BRT results showed somewhat 406 different trends than the other methods in model responses to predictors (Fig. 4). For 407 example, while tree height in spruce forests increases damage probability throughout the 408 range of data in GLM (Fig. 2) and GAM results (Fig. 3), in BRT results similar strongly 409 increasing trend is not found, instead the relationship between height and damage 410 probability seems to saturate for all tree species (Fig. 4). The large-scale spatial patterns in 411 map prediction also differed for BRT compared to the other models, as high values of 412 damage probability were predicted for the northernmost parts of the country. (Fig. 7).

413 Cross-validation showed higher predictive performance of the GAM model compared to the 414 GLM and BRT (Fig. 6). However, when the final damage probability maps were tested with 415 the NFI12 test data, all models showed very similar performance in discriminating between 416 damaged and non-damaged plots in the test data. (Fig. 8). All maps gave on average higher 
417 damage probability values for damaged than non-damaged plots and showed an acceptable

418 level of discrimination between the two (AUC > 0.7). The added flexibility and ability to 419 account for nonlinear relationships in GAM and BRT did not considerably improve the 420 predictive performance of maps compared to the fully parametric GLM (Fig. 8).

\section{4. Discussion}

422

423

424

425

426

427

428

429

430

431

432

433

434

435

436

437

438

439

440

441

442

\subsection{The damage probability map}

We created a new spatial wind damage risk product based on inventory data spanning over several years and several other data spatial sources, including information where the actual harvests have recently occurred in Finland. Validation of the map with independent and large data set showed that the map is able to identify vulnerable stands also in new storm events. While there have been attempts to map wind damage probability based on empirical damage models (Schindler et al., 2009; Saarinen et al., 2016; Suvanto et al., 2016), our work here uniquely provides national extent and high spatial resolution information about forest vulnerability to wind and its validity is also tested with large external test data.

The successful identification of damage vulnerability in an independent test data is not trivial. First of all, wind damage is challenging to predict and extending the performance of statistical wind damage models to new data sets has been shown not to be straightforward (Fridman and Valinger, 1998; Lanquaye-Opoku and Mitchell, 2005; Kamimura et al., 2015). Moreover, because we wanted to test how well our map identifies forest vulnerability to wind in future events, for which we don't have detailed information of, we did not include any information about spatial distribution of wind speeds or storm events during the time frame of the test data when we tested the map. Thus, the discrimination of damaged from nondamaged plots with fair accuracy $(A \cup C=0.726)$ for the entire extent of Finland indicates that the map is indeed successful in identifying the vulnerable forests, and implies that efficient combination of inventory data and several new spatial data sources is a promising way to map damage risks. 
443 A major factor contributing to the successful extension of the map to new test data was the

444 large and systematically sampled forest and damage data that spanned over several years.

445 Thus, our model was able to represent the different conditions (forest characteristics, soil, 446 etc.) within the country. The need for comprehensive model data in empirical wind damage 447 models has been demonstrated, for example, by Hart et al. (2019) who showed that it is 448 possible to generalize to new storm events when the model data covers the variation of 449 predictor variables in the new data set.

In addition to good representation of environmental and forest conditions, our data also represents different types of wind events, since the data consisted of damage observations in a 5-year time window. Most wind disturbance studies typically concentrate on one or few storms (e.g., Schindler et al., 2009; Kamimura et al., 2015; Saarinen et al., 2016; Suvanto et 454 al., 2016; Hart et al., 2019), which limits their ability to generalize to different storm events. While modelling of multi-event data can be more challenging than single-event data (Albrecht et al., 2019), we argue that it is necessary when the purpose of the model is in assessing damage probability in new storm events, outside of the original model data.

Availability of high-quality and high-resolution spatial data of the model predictors was also crucial for the ability of the damage probability map to identify damaged stands in the test data. Additional uncertainties arise from the input data sets when model predictions are made with GIS data gathered from several different sources instead of the field-measured data that were used for fitting the model. In our case, we were able to utilize several highquality and high-resolution data sources, such as the MS-NFI raster maps of forest characteristics (Mäkisara et al., 2019) and new data products of local wind conditions (Venäläinen et al., 2017). We were also able to use the recently opened forest use notification data from the Finnish Forest Centre that provided us with nation-wide information about the recent forest management history of the stands. This type of legacy information about forest management is typically difficult to obtain and has rarely been included in predictive wind damage risk models before, despite the clear effects of management history 
on forest disturbance dynamics. While all these data sources contain uncertainties, the

471 verification of our map with independent test data showed that they were nevertheless able

472 to represent well the main factors determining forest susceptibility to wind.

473 With new data sources and increasing quality and availability of data in the future, the 474 accuracy of the map could still be improved. This could mean, for example, improved 475 accuracy of tree height information through the use of lidar data or inclusion of variables that 476 were left out of the current map due to lack of national level spatial data about their 477 distribution (e.g. distribution of wood decaying fungi that weaken trees' resistance to wind). 478 Soil data had maybe the lowest resolution and higher uncertainties of the used GIS data 479 and, therefore, increased quality of those data sets would also be desirable. However, the 480 effects of soil variables in the model were relatively small, and therefore the effects of only 481 improving the soil GIS data in the prediction would most likely not be drastic. Instead, more 482 detailed soil data would be needed for the model data to improve the description of the role 483 of soil characteristics on tree vulnerability to wind in the model. Integrating projections of 484 future wind climate would also add value to the map, as the current version only uses data 485 describing present wind conditions (that is, the data by Venäläinen et al. 2017).

\subsection{Drivers of forest susceptibility to wind disturbance}

487 The factors that were found to affect damage probability in our results are well in line with 488 previously published results. For example, increasing damage probability with tree height 489 and the higher vulnerability of Norway spruce have been shown in previous studies (Peltola 490 et al., 1999; Valinger and Fridman, 2011; Suvanto et al., 2016). New stand edges after 491 clearcutting of the neighboring stand and recently thinned stands have also been known to 492 be at higher risk of windthrow (Lohmander and Helles, 1987; Peltola et al., 1999; Wallentin 493 and Nilsson, 2014).

494 While open stand edges did increase the risk of wind damage in our results, the effect was 495 not as distinct as could be expected from earlier research that emphasizes the role of forest 
edges (e.g., Peltola et al., 1999). This may in part result from the use of stand level data,

497 where defining and identifying the open stand borders from the NFI data is more uncertain

498 than in the case of tree-level analysis (see section 2.3.2 for the used methodology). Earlier

499 work with storm damage data from severe autumn storms in Finland showed that the effects

500 of open forest edges on damage probability were more emphasized in tree-level analysis

501 (Suvanto et al., 2018) than in the stand-level analysis of the same data (Suvanto et al.,

502 2016). In the future, potential improvements to the presentation of damage probability at the

503 forest edges in the map could be achieved by combining tree-level results or mechanistic

504 approaches to the current stand-level modeling approach.

505 In the model, the effect of wind speed data (Venäläinen et al., 2017) on damage probability

506 showed logical behaviour of increasing damage probability with increasing 10-year return-

507 rates of maximum wind speed. The wind speed data accounts for the effects of topography

508 on general wind conditions, and therefore variables describing topographical conditions were

509 not included in our models, even though they have been shown to be linked with wind

510 damage probability (e.g., Schindler et al., 2009).

511 Variation in wind conditions were accounted for in the models by two variables: 10-year

512 maximum wind speed return-rates, which described the local long-term wind conditions at

513 the plots, and the damage density variable, which was used to account for major storm

514 events during the study period due to the lack of direct wind speed data with sufficient spatial

515 coverage and accuracy. The use of indirect variable (damage density) to account for this has

516 the risk of not representing the occurred wind conditions well enough, and thus distorting the

517 estimates of other predictors. However, in our results the damage density variable seems to

518 have filled its purpose, as the relationships between predictors and damage density are well

519 in line with previous research and the maps resulting from the models are able to identify the

520 vulnerable stands also in the test data, in which the plots have been affected by different storm events. 
522 Large-scale geographical patterns in our results showed that the probability of wind damage

523 in Finland decreases from south to north. This is in agreement with results from previous

524 studies combining forest model simulations with mechanistic wind damage models (Peltola

525 et al., 2010; Ikonen et al., 2017). The higher susceptibility of forests in southern Finland to 526 wind disturbances is related to the shorter length of the soil frost period in southern parts of

527 the country. When the soil is frozen, trees are well anchored to the ground and less 528 vulnerable to windthrow and, therefore, forests located in areas with longer periods of soil

529 frost are less likely to be damaged during winter storms (Gregow et al., 2011; Laapas et al., 530 2019). However, other factors affecting forest wind susceptibility also change along the 531 north-south gradient. The proportion of Scots pine, a species more resistant to wind than 532 Norway spruce, increases towards north, and trees in the north have on average lower 533 height-to-diameter ratio, which is linked to wind damage sensitivity (Peltola et al., 2010; 534 Ikonen et al., 2017). In addition, in southern parts of the country, forest stands are smaller in 535 area and there are less protected areas compared to the north. Thus, more frequent 536 windthrows related to new stand edges and recent thinnings may also contribute to higher 537 damage probability in the south. Similarly, butt rot caused by Heterobasidion sp., which 538 increases tree vulnerability to wind (Honkaniemi et al., 2017), currently affects the southern 539 parts of the country more severely (Mattila and Nuutinen, 2007; Müller et al., 2018) and may 540 also contribute to the north-south pattern in the wind damage probability in our results.

541 Therefore, it is not entirely clear what are the exact mechanisms causing increased damage 542 probability with temperature sum in our model.

\subsection{Comparison of methods}

544 While the results for GLM and GAM models were rather similar, the BRT showed somewhat 545 different model behaviour in the responses of damage probability to the predictors (Fig. 4) 546 and different patterns in the spatial prediction (Fig. 7). Since the visible differences in the 547 predictions are in the northernmost part of the country, the lack of test data in this area (see

548 S5) makes the interpretation of the test results (Fig. 8) for the BRT challenging, as the area 
549 with unexpected BRT predictions is mainly not covered by the test data. In any case, the

550 high values of BRT predictions in northernmost Finland do not seem realistic.

551 Our results did not show improved predictive performance of the map with the more flexible

552 methods, GAM and BRT, compared to the logistic regression model (GLM). This is

553 somewhat surprising, especially in the case of BRTs, as they are able to account for non-

554 linearity and interactions between predictors flexibly and this has been seen as an

555 advantage leading to more accurate predictions (Elith et al. 2006, 2008, Díaz-Yáñes et al.

556 2019). It seems that while BRT has advantages in accounting for more complex

557 relationships and interactions in the data, they may also catch patterns that are not helpful

558 for making predictions for test data (see, e.g., the unrealisticly high probabilities of damage

559 with very low wind speeds in BRT, Fig. 4). This is likely to hamper the performance of BRTs

560 in our study so that they are not able to improve cross-validation performance compared to

561 GLM.

562 While Díaz-Yáñes et al. (2019) used BRTs for modelling wind and snow data using NFI data,

563 they unfortunately did not compare the method to other methods, report metrics about how

564 well the models predicted damage occurrence or test their results with independent data,

565 which makes the comparison to our results difficult. Several recent studies have shown good

566 performance of RF for modelling storm disturbances (Albrecht et al., 2019; Hart et al., 2019;

567 Kabir et al., 2018). RF is a tree-based ensemble method that has similarities to BRT in the

568 aspect that it also combines a large number of regression trees in order to create accurate

569 predictions. Yet, in our results BRT did not lead to better predictive performance in cross-

570 validation or with test data compared to the two other tested methods.

571 The comparison to the studies finding good results with RF is complicated due to the

572 differences between the methods, even if they have also similarities. Our analysis differs

573 also from that of (Albrecht et al., 2019; Hart et al., 2019; Kabir et al., 2018) on a few other

574 aspects. First, we modelled wind damage on the level of forest stands, whereas the above 
575 mentioned studies were operating on tree-level. Second, we were using longer term NFI

576 damage observations whereas most others used data from specific storm events. However,

577 the study by Albrecht et al. (2019) contained both event-specific and non-event-specific data

578 and they found random forests to outperform GLMs in both types of data. Third, we

579 performed the cross-validation without considering the spatial variation in the storm

580 conditions (the damage density variable in our analysis). This was done because we did not

581 want to use this variable in the prediction, as the final aim was to generalize the results to

582 future damage events, where this information would not be available. It is possible that this

583 approach is disadvantageous to the BRT.

584 While the above mentioned studies did find machine learning methods outperform logistic

585 models in many ways, they also showed some positive sides of the logistic models. Most

586 importantly, even though random forests showed superior performance when cross-

587 validating models with data from one storm event in Hart et al. (2019), logistic models

588 showed the highest AUC values compared to the other methods when the model was

589 applied to another storm event, supporting the value of GLMs when generalizing the results

590 to new storm events.

591 Use of GLMs has the extra benefit of being more easily communicated to the end user, and 592 they can be easily applied to new use cases when model coefficient estimates are 593 published. The interpretation of relationships between predictors and the response variable

594 is more straightforward, whereas especially in BRTs very small changes in e.g. tree height

595 can lead to drastic changes in model prediction (Fig. 4). The unexpectedly high damage

596 probability values in northern Finland also demonstrate the unpredictability of BRT model

597 behaviour. This aspect is particularly important when the end product is meant to be used in 598 practical applications. 
600 The strength of the map is in its high resolution and large extent. The high-resolution makes

601 it useful for assessing wind damage susceptibility of individual forest stands in fragmented

602 forest landscapes where spatial variation of forest characteristics is high. On the other hand,

603 the national extent of the map makes it widely available and accessible to everyone who is

604 making forest management decisions in Finnish forests. To further improve the accessibility

605 and usability of the map, we created an openly available web map application, where users

606 can explore the map and find the estimated wind damage vulnerabilities of the forests they

607 are interested in, without expert knowledge in GIS software (see

608 https://metsainfo.luke.fi/en/tuulituhoriskikartta, currently only in Finnish, click "Tuulituhoriskit"

609 to see the wind damage vulnerability map). By providing an effective tool for identifying the

610 vulnerable stands and for communicating wind damage risks to forest managers and

611 owners, the map has potential to steer forest management practices towards a more

612 disturbance-aware direction.

613 In addition to forest management, high-resolution information about forest wind vulnerability

614 is crucially needed also in other sectors and applications. For example, the map can help in

615 identifying high-risk locations where windthrown trees can harm infrastructure by damaging

616 power lines and blocking roads. Insurance companies may also use high-resolution

617 vulnerability information for a more risk-based pricing of forest insurances.

618 While wind disturbances have major consequences from the human point of view, they are a

619 natural process and have an important role in shaping the structure and function of forest ecosystems (Bouget and Duelli, 2004; Kuuluvainen, 2002). By exploring the drivers and spatial variability of wind disturbance dynamics, our results can therefore provide insight in

622 current disturbance regime and its effects in the ecosystem, such as biodiversity and carbon

623 cycling. Improved information about forest disturbances and tree mortality is also urgently

624 needed for vegetation models from stand to global scales to understand how forests will

625 react to the changing climate (Bugmann et al., 2019; Friend et al., 2014). 
626 When applying the map in practice, it is important to consider its limitations. First, the

627 damage probabilities in the map are in reference to the damage happened during the study

628 period. The amount of wind damage varies strongly between years and future conditions are

629 not likely to exactly match the conditions during the period from which the data comes from.

630 Therefore, instead of exact probability values, it is better to interpret the map values as

631 relative differences in damage vulnerability. Second, it is important to note that the damage

632 probabilities do not only refer to complete damage of the stand, as our analysis also included

633 less severe damage cases and we did not account for damage severity. Third, it is good to

634 keep in mind that the map presents forest vulnerability to wind and it is not possible to

635 predict the exact location of future wind disturbances, as there are many things - such as

636 tracks and meteorological conditions of future storms - that cannot be accounted for in the

637 map. The uncertainties need to be taken into consideration when using the map.

638 Wind disturbances are strongly linked to other processes of the forest and, therefore, should 639 be considered in larger context. Thus, the greatest benefits of our results can perhaps be 640 achieved by combining them with information and understanding of other processes that 641 control forest ecosystems and forest management decisions. For example, the risk model 642 can be coupled with forest growth simulators and thereafter storm damage risks of different 643 forest management strategies can be evaluated simultaneously when making future 644 scenarios of forests. The map can be combined with spatial information of wood volumes 645 and prices to assess economic risks wind disturbances. Combining wind disturbance results 646 with the dynamics of other disturbance agents is also crucial, as wind damage is strongly 647 linked to bark beetle outbreaks and root rot, and these interactions are becoming 648 increasingly important with the changing climate (Seidl et al., 2017; Seidl and Rammer, 649 2017). A comprehensive approach is therefore needed to understand and effectively 650 manage wind disturbances in forests.

\section{5. Conclusions}


652 In this study, we show how damage probability models based on NFI damage observations

653 combined with existing spatial datasets can be used to provide a fine-scale large-extent map

654 of wind disturbance probability. We also demonstrate the ability of the map to identify 655 vulnerable stands in future events with an extensive external test data. These maps provide 656 a powerful tool for supporting disturbance-aware management decisions, communicating 657 disturbance risks to forest owners, and accounting for the effects of windthrown trees in 658 other sectors, such as maintenance of powerline infrastructures.

659 Our results show that more flexible methods, such as GAM and BRT, do not always provide superior results compared to parametric statistical models, such as GLM. As the interpretation of these methods can be less straightforward, they can sometimes lead to unpredictable prediction outcomes. Therefore, it is crucial to always assess the benefits of different approaches and to carefully test the performance of the used method with test data that is not used in model fitting. Partial dependence plots and other ways for exploration of model predictions in different situations also provide useful tools for assessing if model behaviour is realistic and biologically plausible.

The success of our results is based on large and representative model data as well as highquality and high-resolution GIS data used as map inputs. In Finland, good data sets for both the model fitting and the map inputs are available, which provided a good starting point for the work done in this study. Even though the study here was conducted for Finland, the

671 results have high international relevance, showing that in spite of the inherent stochasticity of

672 the wind and damage phenomena at all spatial scales, wind damage can be modelled with 673 good accuracy across large spatial scales when existing ground and earth observation data 674 sources are combined smartly. With improving data quality and availability (for both damage 675 observations for model fitting and GIS data for map inputs), similar work can be extended to 676 other regions and to other disturbance types.

677 Acknowledgements 
678 The research was co-funded by the Finnish Forest Foundation (project MyrskyPuu). We 679 thank Ari Venäläinen and Mikko Laapas from the Finnish Meteorological Institute for their 680 advice and the maximum wind speed 10-year return level data, and the MyrskyPuu project 681 steering group (Liisa Mäkijärvi, Erno Järvinen, Heli Peltola, Ari Venäläinen and Eero Mikkola) 682 for the discussions and their insights on the topic. We also thank Kari T. Korhonen for his 683 comments on the manuscript and the whole NFI team in Luke for the NFI data we were able 684 to use in the study. We acknowledge CSC - IT Center for Science, Finland, for 685 computational resources. 
Aalto, J., Pirinen, P., Jylhä, K., 2016. New gridded daily climatology of Finland: Permutation689 based uncertainty estimates and temporal trends in climate. J. Geophys. Res. Atmospheres 121, 3807-3823. https://doi.org/10.1002/2015JD024651

Albrecht, A.T., Jung, C., Schindler, D., 2019. Improving empirical storm damage models by coupling with high-resolution gust speed data. Agric. For. Meteorol. 268, 23-31. https://doi.org/10.1016/j.agrformet.2018.12.017

Andersson, E., Keskitalo, E.C.H., Bergstén, S., 2018. In the eye of the storm: adaptation 695 logics of forest owners in management and planning in Swedish areas. Scand. J.

696 For. Res. 33, 800-808. https://doi.org/10.1080/02827581.2018.1494305

Bates, D., Mächler, M., Bolker, B., Walker, S., 2015. Fitting Linear Mixed-Effects Models Using Ime4. J. Stat. Softw. 67, 1-48. https://doi.org/10.18637/jss.v067.i01

Bouget, C., Duelli, P., 2004. The effects of windthrow on forest insect communities: a literature review. Biol. Conserv. 118, 281-299. https://doi.org/10.1016/j.biocon.2003.09.009

Bugmann, H., Seidl, R., Hartig, F., Bohn, F., Brůna, J., Cailleret, M., François, L., Heinke, J., 704 Henrot, A.-J., Hickler, T., Hülsmann, L., Huth, A., Jacquemin, I., Kollas, C., LaschBorn, P., Lexer, M.J., Merganič, J., Merganičová, K., Mette, T., Miranda, B.R., NadalSala, D., Rammer, W., Rammig, A., Reineking, B., Roedig, E., Sabaté, S., Steinkamp, J., Suckow, F., Vacchiano, G., Wild, J., Xu, C., Reyer, C.P.O., 2019. Tree

Díaz-Yáñez, O., Mola_Yudego, M., González-Olabarria, J.B. (2019). Modelling damage occurrence by snow and wind in forest ecosystems. Ecological Modelling 408, 108741. mortality submodels drive simulated long-term forest dynamics: assessing 15 models from the stand to global scale. Ecosphere 10, e02616. https://doi.org/10.1002/ecs2.2616

Dobbertin, M., 2002. Influence of stand structure and site factors on wind damage comparing 

the storms Vivian and Lothar. For. Snow Landsc. Res. 77, 187-205.

715 Elith, J., Graham, C.H., Anderson, R.P. Dudík, M., Ferrier, S., Guisan, A., Hijmans, R.J.,

716 Huettmann, F., Leathwick, J.R., Lehmann, A., Li, J., Lohmann, L.G., Loiselle, B.A., Manion, G., Moritz, C., Nakamura, M., Nakazawa, Y., Overton, J.M.M., Peterson, A.T., Phillips, S.J., Richardson, K., Scachetti-Pereira, R., Schapire, R.E., Soberón, J., Williams, S., Wisz, M.S., Zimmermann, N.E., 2006. Novel methods improve prediction of species' distributions from occurrence data. Ecography 29, 129-151.

Elith, J., Leathwick, J.R., Hastie, T., 2008. A working guide to boosted regression trees. J. Anim. Ecol. 77, 802-813. https://doi.org/10.1111/j.1365-2656.2008.01390.x

Fox, J., Monette, G., 1992. Generalized Collinearity Diagnostics. J. Am. Stat. Assoc. 87, 178-183. https://doi.org/10.1080/01621459.1992.10475190

Fridman, J., Valinger, E., 1998. Modelling probability of snow and wind damage using tree, stand, and site characteristics from Pinus sylvestris sample plots. Scand. J. For. Res. 13, 348-356. https://doi.org/10.1080/02827589809382994

Friend, A.D., Lucht, W., Rademacher, T.T., Keribin, R., Betts, R., Cadule, P., Ciais, P., Clark, D.B., Dankers, R., Falloon, P.D., Ito, A., Kahana, R., Kleidon, A., Lomas, M.R., Nishina, K., Ostberg, S., Pavlick, R., Peylin, P., Schaphoff, S., Vuichard, N., Warszawski, L., Wiltshire, A., Woodward, F.I., 2014. Carbon residence time dominates uncertainty in terrestrial vegetation responses to future climate and atmospheric CO2. Proc. Natl. Acad. Sci. 111, 3280-3285. https://doi.org/10.1073/pnas.1222477110

Gregow, H., Laaksonen, A., Alper, M.E., 2017. Increasing large scale windstorm damage in Western, Central and Northern European forests, 1951-2010. Sci. Rep. 7, 46397. https://doi.org/10.1038/srep46397

Gregow, H., Peltola, H., Laapas, M., Saku, S., Venäläinen, A., 2011. Combined occurrence of wind, snow loading and soil frost with implications for risks to forestry in Finland under the current and changing climatic conditions. Silva Fenn. 45. https://doi.org/10.14214/sf.30 
GTK, 2018. Superficial deposits of Finland 1:200 000 (sediment polygons). http://tupa.gtk.fi/paikkatieto/meta/maapera_200k.html (accessed 4.29.19).

744 Hanewinkel, M., Zhou, W., Schill, C., 2004. A neural network approach to identify forest stands susceptible to wind damage. For. Ecol. Manag. 196, 227-243. https://doi.org/10.1016/j.foreco.2004.02.056

Hart, E., Sim, K., Kamimura, K., Meredieu, C., Guyon, D., Gardiner, B., 2019. Use of machine learning techniques to model wind damage to forests. Agric. For. Meteorol. 265, 16-29. https://doi.org/10.1016/j.agrformet.2018.10.022

Hastie, T., Tibshirani, R., Friedman, J., 2009. The elements of statistical learning, 2nd ed, Springer Series in Statistics. Springer-Verlag New York.

Hijmans, R.J., 2017. raster: Geographic Data Analysis and Modeling. R package version 753 2.6-7. https://CRAN.R-project.org/package=raster.

Hijmans, R.J., Phillips, S., Leathwick, J., Elith, J., 2017. dismo: Species Distribution Modeling. R package version 1.1-4. https://CRAN.R-project.org/package=dismo.

Honkaniemi, J., Lehtonen, M., Väisänen, H., Peltola, H., 2017. Effects of wood decay by Heterobasidion annosum on the vulnerability of Norway spruce stands to wind damage: a mechanistic modelling approach. Can. J. For. Res. 47, 777-787. https://doi.org/10.1139/cjfr-2016-0505

Hosmer, D.W., Lemeshow, S., Strudivant, R.X., 2013. Applied Logistic Regression, 3rd ed. John Wiley \& Sons, New York.

Ikonen, V.-P., Kilpeläinen, A., Zubizarreta-Gerendiain, A., Strandman, H., Asikainen, A., Venäläinen, A., Kaurola, J., Kangas, J., Peltola, H., 2017. Regional risks of wind damage in boreal forests under changing management and climate projections. Can. J. For. Res. 47, 1632-1645. https://doi.org/10.1139/cjfr-2017-0183

Kabir, E., Guikema, S., Kane, B., 2018. Statistical modeling of tree failures during storms. Reliab. Eng. Syst. Saf. 177, 68-79. https://doi.org/10.1016/j.ress.2018.04.026 statistical approaches to predicting wind damage to individual maritime pine (Pinus 

2015-0237

772

773

774

775

776

777

778

779

780

781

782

783

784

785

786

787

788

789

790

791

792

793

794

795

796

797

Korhonen, K.T., 2016. National forest inventories : Assessment of wood availability and use : Finland, in: Vidal, C., Alberdi, I., Hernández, L., Redmond, J.J. (Eds.), National Forest Inventories: Assessment of Wood Availability and Use. Springer International Publishing, Switzerland, pp. 369-384.

Korhonen, K.T., Ihalainen, A., Ahola, A., Heikkinen, J., Henttonen, H.M., Hotanen, J.-P., Nevalainen, S., Pitkänen, J., Strandström, M., Viiri, H., 2017. Suomen metsät 2009_ 2013 ja niiden kehitys 1921-2013 (No. 59/2017), Luonnonvara- ja biotalouden tutkimus. Natural Resources Institute Finland (Luke).

Kufeoglu, S., Lehtonen, M. (2014). Cyclone Dagmar of 2011 and its impacts in Finland. 5th IEEE PES Innovative Smart Grid Technologies Europe (ISGT Europe), October 1215 , Istanbul.

Kuuluvainen, T., 2002. Disturbance dynamics in boreal forests: defining the ecological basis of restoration and management of biodiversity. Silva Fenn. 36, 5-11.

Laapas, M., Lehtonen, I., Venäläinen, A., Peltola, H.M., 2019. The 10-Year Return Levels of Maximum Wind Speeds under Frozen and Unfrozen Soil Forest Conditions in Finland. Climate 7, 62. https://doi.org/10.3390/cli7050062

Lanquaye-Opoku, N., Mitchell, S.J., 2005. Portability of stand-level empirical windthrow risk models. For. Ecol. Manag. 216, 134-148. https://doi.org/10.1016/j.foreco.2005.05.032

Lohmander, P., Helles, F., 1987. Windthrow probability as a function of stand characteristics and shelter. Scand. J. For. Res. 2, 227-238. https://doi.org/10.1080/02827588709382460

Mäkisara, K., Katila, M., Peräsaari, J., 2019. The Multi-Source National Forest Inventory of Finland - methods and results 2015 (No. 8/2019), Natural Resources and Bioeconomy Studies. Natural Resources Institute Finland (Luke).

Mäkisara, K., Katila, M., Tomppo, E., 2016. The Multi-Source National Forest Inventory of 

Finland - methods and results 2013 (No. 10/2016), Natural Resources and Bioeconomy Studies. Natural Resources Institute Finland (Luke).

800 Mattila, U., Nuutinen, T., 2007. Assessing the incidence of butt rot in Norway spruce in 801 southern Finland. Silva Fenn. 41. https://doi.org/10.14214/sf.473

802

Mitchell, S.J., 2013. Wind as a natural disturbance agent in forests: a synthesis. For. Int. J.

803 For. Res. 86, 147-157. https://doi.org/10.1093/forestry/cps058

Müller, M.M., Henttonen, H.M., Penttilä, R., Kulju, M., Helo, T., Kaitera, J., 2018. Distribution of Heterobasidion butt rot in northern Finland. For. Ecol. Manag. 425, 85-91.

806 https://doi.org/10.1016/j.foreco.2018.05.047

Nakou, A., Sauter, U.H., Kohnle, U., 2016. Improved models of harvest-induced bark 808 damage. Ann. For. Sci. 73, 233-246. https://doi.org/10.1007/s13595-015-0530-5

Narendra, P.M., Goldberg, M., 1980. Image Segmentation with Directed Trees. IEEE Trans. Pattern Anal. Mach. Intell. PAMI-2, 185-191. https://doi.org/10.1109/TPAMI.1980.4766999

812 Nicoll, B.C., Gardiner, B.A., Rayner, B., Peace, A.J., 2006. Anchorage of coniferous trees in 813 relation to species, soil type, and rooting depth. Can. J. For. Res. 36, 1871-1883.

814 NLS, 2018. Topographic Database https://www.maanmittauslaitos.fi/en/maps-and-spatial815 data/expert-users/product-descriptions/topographic-database.

816 Pebesma, E.J., Bivand, R.S., 2005. Classes and methods for spatial data in R (No. 5 (2), https://cran.r-project.org/doc/Rnews/), R News.

818 Pekkarinen, A., 2002. Image segment-based spectral features in the estimation of timber 819 volume. Remote Sens. Environ. 82, 349-359. https://doi.org/10.1016/S00344257(02)00052-4

Peltola, H., Ikonen, V.-P., Gregow, H., Strandman, H., Kilpeläinen, A., Venäläinen, A., 822 Kellomäki, S., 2010. Impacts of climate change on timber production and regional risks of wind-induced damage to forests in Finland. For. Ecol. Manag. 260, 833-845. https://doi.org/10.1016/j.foreco.2010.06.001

825 Peltola, H., Kellomäki, S., Väisänen, H., Ikonen, V.-P., 1999. A mechanistic model for 

assessing the risk of wind and snow damage to single trees and stands of Scots pine, Norway spruce, and birch. Can. J. For. Res. 29, 647-661. https://doi.org/10.1139/x99-029

R Core Team, 2018. R: A language and environment for statistical computing. R Foundation for Statistical Computing, Vienna, Austria. https://www.R-project.org/.

Reyer, C.P.O., Bathgate, S., Blennow, K., Borges, J.G., Bugmann, H., Delzon, S., Faias, S.P., Garcia-Gonzalo, J., Gardiner, B., Gonzalez-Olabarria, J.R., Gracia, C., Hernández, J.G., Kellomäki, S., Kramer, K., Lexer, M.J., Lindner, M., Maaten, E. van der, Maroschek, M., Muys, B., Nicoll, B., Palahi, M., Palma, J.H., Paulo, J.A., Peltola, H., Pukkala, T., Rammer, W., Ray, D., Sabaté, S., Schelhaas, M.-J., Seidl, R., Temperli, C., Tomé, M., Yousefpour, R., Zimmermann, N.E., Hanewinkel, M., 2017. Are forest disturbances amplifying or canceling out climate change-induced productivity changes in European forests? Environ. Res. Lett. 12, 034027. https://doi.org/10.1088/1748-9326/aa5ef1

Robin, X., Turck, N., Hainard, A., Tiberti, N., Lisacek, F., Sanchez, J.-C., Müller, M., 2011. pROC: an open-source package for R and $\mathrm{S}+$ to analyze and compare ROC curves. BMC Bioinformatics 12, 77. https://doi.org/10.1186/1471-2105-12-77

Saarinen, N., Vastaranta, M., Honkavaara, E., Wulder, M.A., White, J.C., Litkey, P., Holopainen, M., Hyyppä, J., 2016. Using multi-source data to map and model the predisposition of forests to wind disturbance. Scand. J. For. Res. 31, 66-79. https://doi.org/10.1080/02827581.2015.1056751

Schelhaas, M.-J., Nabuurs, G.-J., Schuck, A., 2003. Natural disturbances in the European forests in the 19th and 20th centuries. Glob. Change Biol. 9, 1620-1633. https://doi.org/10.1046/j.1365-2486.2003.00684.x

Schindler, D., Grebhan, K., Albrecht, A., Schönborn, J., 2009. Modelling the wind damage probability in forests in Southwestern Germany for the 1999 winter storm 'Lothar.' Int. J. Biometeorol. 53, 543-554. https://doi.org/10.1007/s00484-009-0242-3

Schindler, D., Jung, C., Buchholz, A., 2016. Using highly resolved maximum gust speed as 

predictor for forest storm damage caused by the high-impact winter storm Lothar in Southwest Germany. Atmospheric Sci. Lett. 17, 462-469. https://doi.org/10.1002/asl.679

Schmidt, M., Hanewinkel, M., Kändler, G., Kublin, E., Kohnle, U., 2010. An inventory-based approach for modeling single-tree storm damage - experiences with the winter storm of 1999 in southwestern Germany. Can. J. For. Res. 40, 1636-1652. https://doi.org/10.1139/X10-099

Seidl, R., Rammer, W., 2017. Climate change amplifies the interactions between wind and bark beetle disturbances in forest landscapes. Landsc. Ecol. 32, 1485-1498. https://doi.org/10.1007/s10980-016-0396-4

Seidl, R., Schelhaas, M.-J., Lexer, M.J., 2011. Unraveling the drivers of intensifying forest disturbance regimes in Europe. Glob. Change Biol. 17, 2842-2852. https://doi.org/10.1111/j.1365-2486.2011.02452.x

Seidl, R., Schelhaas, M.-J., Rammer, W., Verkerk, P.J., 2014. Increasing forest disturbances in Europe and their impact on carbon storage. Nat. Clim. Change 4, 806-810. https://doi.org/10.1038/nclimate2318

Seidl, R., Thom, D., Kautz, M., Martin-Benito, D., Peltoniemi, M., Vacchiano, G., Wild, J., Ascoli, D., Petr, M., Honkaniemi, J., Lexer, M.J., Trotsiuk, V., Mairota, P., Svoboda, M., Fabrika, M., Nagel, T.A., Reyer, C.P.O., 2017. Forest disturbances under climate change. Nat. Clim. Change 7, 395-402. https://doi.org/10.1038/nclimate3303

Suvanto, S., Henttonen, H.M., Nöjd, P., Mäkinen, H., 2018. High-resolution topographical information improves tree-level storm damage models. Can. J. For. Res. 48, 721728. https://doi.org/10.1139/cjfr-2017-0315

Suvanto, S., Henttonen, H.M., Nöjd, P., Mäkinen, H., 2016. Forest susceptibility to storm damage is affected by similar factors regardless of storm type: Comparison of thunder storms and autumn extra-tropical cyclones in Finland. For. Ecol. Manag. 381, 17-28. https://doi.org/10.1016/j.foreco.2016.09.005

Tomppo, E., Haakana, M., Katila, M., Peräsaari, J., 2008. Multi-Source National Forest 

Netherlands.

884 Tomppo, E., Heikkinen, J., Henttonen, H.M., Ihalainen, A., Katila, M., Mäkelä, H., 885 Tuomainen, T., Vainikainen, N., 2011. Designing and Conducting a Forest Inventory 886 case: 9th National Forest Inventory of Finland, Managing Forest Ecosystems.

887 Springer Netherlands.

Valinger, E., Fridman, J., 2011. Factors affecting the probability of windthrow at stand level as a result of Gudrun winter storm in southern Sweden. For. Ecol. Manag. 262, 398403. https://doi.org/10.1016/j.foreco.2011.04.004

Valinger, E., Fridman, J., 1997. Modelling probability of snow and wind damage in Scots 892 pine stands using tree characteristics. For. Ecol. Manag. 97, 215-222. https://doi.org/10.1016/S0378-1127(97)00062-5

Valinger, E., Kempe, G., Fridman, J., 2014. Forest management and forest state in southern Sweden before and after the impact of storm Gudrun in the winter of 2005. Scand. J. For. Res. 29, 466-472. https://doi.org/10.1080/02827581.2014.927528

Venäläinen, A., Laapas, M., Pirinen, P., Horttanainen, M., Hyvönen, R., Lehtonen, I., Junila, 898 P., Hou, M., Peltola, H.M., 2017. Estimation of the high-spatial-resolution variability in extreme wind speeds for forestry applications. Earth Syst. Dyn. 8, 529-545. https://doi.org/10.5194/esd-8-529-2017

Viiri, H., Ahola, A., Ihalainen, A., Korhonen, K.T., Muinonen, E., Parikka, H., Pitkänen, J., 903 2011. Kesän 2010 myrskytuhot ja niistä seuraava hyönteistuhoriski (In Finnish). Metsätieteen aikakauskirja 3, 221-225.

Wallentin, C., Nilsson, U., 2014. Storm and snow damage in a Norway spruce thinning experiment in southern Sweden. For. Int. J. For. Res. 87, 229-238. https://doi.org/10.1093/forestry/cpt046

Wand, M., 2015. KernSmooth: Functions for Kernel Smoothing Supporting Wand \& Jones (1995), R package version 2.23-15. https://CRAN.Rproject.org/package=KernSmooth. 
910 Wood, S., 2017. Generalized Additive Models: An Introduction with R, Second Edition, 2nd

$911 \quad$ edition. ed.

912 Wood, S.N., 2011. Fast stable restricted maximum likelihood and marginal likelihood

913 estimation of semiparametric generalized linear models. J. R. Stat. Soc. Ser. B Stat.

$914 \quad$ Methodol. 73, 3-36.

915 Wood, S.N., Scheipl, F., 2017. gamm4: Generalized Additive Mixed Models using "mgcv"

916 and "Ime4". R package version 0.2-5. https://CRAN.R-project.org/package=gamm4.

917 


\section{Tables}

919 Table 1. Description of predictors used and their sources in the model and in the damage 920 probability map. See section 2.2.1 for details. Abbreviations: NFI11 $-11^{\text {th }}$ Finnish National 921 Forest Inventory, NFI12 $-12^{\text {th }}$ Finnish National Forest Inventory, MS-NFI - multi-source NFI, 922 GTK - Geological Survey of Finland, NLS - National Land Survey of Finland.

\begin{tabular}{|c|c|c|c|c|}
\hline Variable & Type* & Unit / Classes & Source in model & Source in map \\
\hline Tree species & C & $\begin{array}{l}\text { pine, spruce, } \\
\text { other }\end{array}$ & NFI11 & MS-NFI 2015 \\
\hline Tree height & $\mathrm{N}$ & $\mathrm{dm}$ & NFI11 & MS-NFI 2015 \\
\hline $\begin{array}{l}\text { Time since } \\
\text { thinning }\end{array}$ & C & $\begin{array}{l}0-5,6-10 \\
>10 \text { years }\end{array}$ & NFI11 & $\begin{array}{l}\text { MS-NFI } 2015 \\
\text { Forest use notifications }\end{array}$ \\
\hline $\begin{array}{l}\text { Wind (10-year } \\
\text { return level of } \\
\text { max wind speed) }\end{array}$ & $\mathrm{N}$ & $\mathrm{ms}^{-1}$ & $\begin{array}{l}\text { Venäläinen et al. } \\
2017\end{array}$ & Venäläinen et al. 2017 \\
\hline $\begin{array}{l}\text { Open neighbor } \\
\text { stand }\end{array}$ & C & True, False & MS-NFI 2013 & MS-NFI 2015 \\
\hline Soil type & C & $\begin{array}{l}\text { Mineral/coarse, } \\
\text { Mineral/fine, } \\
\text { Organic }\end{array}$ & NFI11 & $\begin{array}{l}\text { GTK 2018, } \\
\text { NLS } 2018\end{array}$ \\
\hline $\begin{array}{l}\text { Mineral soil depth } \\
<30 \mathrm{~cm}\end{array}$ & C & True, False & NFI11 & $\begin{array}{l}\text { GTK 2018, } \\
\text { NLS } 2018\end{array}$ \\
\hline Site fertility & C & Fertile, Poor & NFI11 & MS-NFI 2015 \\
\hline $\begin{array}{l}\text { Temperature sum } \\
\text { (average 1985- } \\
\text { 2014) }\end{array}$ & $\mathrm{N}$ & $\begin{array}{l}100 \text { dd (over } \\
5 \mathrm{C})\end{array}$ & Aalto et al. 2016 & Aalto et al. 2016 \\
\hline $\begin{array}{l}\text { Damage density } \\
\text { ratio }\end{array}$ & C & $0-2,2-3,<3$ & NFI11 & $\begin{array}{l}\text { In the calculation of the } \\
\text { map, this variable was } \\
\text { included as a weighted } \\
\text { average of all classes, } \\
\text { because it was included in } \\
\text { the model only to account } \\
\text { for spatial structures in } \\
\text { storm severity. }\end{array}$ \\
\hline
\end{tabular}


924 Table 2. Descriptive statistics for the NFI11 data. Mean and standard deviation for non925 damaged, damaged and all plots continuous variables, and percentages of each class for 926 categorical variables. The definitions of the variables are in table 1.

\begin{tabular}{|c|c|c|c|}
\hline & Non-damaged & Damaged & All \\
\hline Number of plots & 40322 & 1070 & 41392 \\
\hline \multicolumn{4}{|l|}{ Species } \\
\hline Scots pine & $63.4 \%$ & $59.1 \%$ & $63.3 \%$ \\
\hline Norway spruce & $24.0 \%$ & $36.8 \%$ & $24.3 \%$ \\
\hline Other & $12.6 \%$ & $4.1 \%$ & $12.4 \%$ \\
\hline Tree height & $163.0(50.5)$ & $195.2(45.1)$ & $163.9(50.6)$ \\
\hline \multicolumn{4}{|l|}{ Time since thinning } \\
\hline $0-5$ years & $13.4 \%$ & $26.0 \%$ & $13.7 \%$ \\
\hline $6-10$ years & $9.2 \%$ & $15.5 \%$ & $9.4 \%$ \\
\hline$>10$ years & $77.4 \%$ & $58.5 \%$ & $76.9 \%$ \\
\hline Wind & $12.1(2.0)$ & $12.5(2.0)$ & $12.2(2.0)$ \\
\hline \multicolumn{4}{|l|}{ Open neighbor } \\
\hline False & $85.7 \%$ & $84.6 \%$ & $85.7 \%$ \\
\hline True & $14.3 \%$ & $15.4 \%$ & $14.3 \%$ \\
\hline \multicolumn{4}{|l|}{ Soil type } \\
\hline Mineral, coarse & $66.9 \%$ & $77.8 \%$ & $67.2 \%$ \\
\hline Mineral, fine & $12.7 \%$ & $9.8 \%$ & $12.7 \%$ \\
\hline Organic & $20.3 \%$ & $12.4 \%$ & $20.1 \%$ \\
\hline \multicolumn{4}{|l|}{ Soil depth $<30 \mathrm{~cm}$} \\
\hline False & $89.5 \%$ & $85.0 \%$ & $89.4 \%$ \\
\hline True & $10.5 \%$ & $15.0 \%$ & $10.6 \%$ \\
\hline \multicolumn{4}{|l|}{ Site fertility } \\
\hline Poor & $34.8 \%$ & $31.9 \%$ & $34.7 \%$ \\
\hline Fertile & $65.2 \%$ & $68.1 \%$ & $65.3 \%$ \\
\hline Temperature sum & $1,185(178.9)$ & $1,262.6(130.4)$ & $1,187.0(178.3)$ \\
\hline
\end{tabular}


928 Table 3. GLM model results. See Table 1 for descriptions of variables. For categorical 929 variables, the first class listed in Table 1 is the reference class and not listed separately in 930 this table, i.e., the results of other classes are presented in reference to the reference class. 931 Classes of categorical variables are presented as subscripts. Colons are used to present 932 interaction terms between variables.

\begin{tabular}{|c|c|c|c|c|}
\hline & Estimate & Std. Error & $z$ value & $\operatorname{Pr}(>P Q \beta)$ \\
\hline (Intercept) & -14.690 & 1.061 & -13.841 & $<0.0334$ \\
\hline Species $_{\text {Spruce }}$ & -8.494 & 1.918 & -4.430 & $<0.001$ \\
\hline Species $_{\text {Other }}$ & -9.314 & 3.931 & -2.370 & 0.018 \\
\hline $\log ($ Height $)$ & 1.661 & 0.189 & 8.807 & $<0.001$ \\
\hline Last thinning $_{6-10 \text { years }}$ & -0.298 & 0.113 & -2.637 & 0.008 \\
\hline Last thinning ${ }_{\text {over } 10}$ years & -0.844 & 0.084 & -9.995 & $<0.001$ \\
\hline $\log ($ Wind $)$ & 0.749 & 0.238 & 3.152 & 0.002 \\
\hline Open stand border $r_{\text {TRUE }}$ & 0.310 & 0.095 & 3.284 & 0.001 \\
\hline Soil $\left.\right|_{\text {mineral, fine }}$ & -0.356 & 0.124 & -2.875 & 0.004 \\
\hline Soil ${ }_{\text {organic }}$ & -0.216 & 0.110 & -1.962 & 0.050 \\
\hline Soil depth $<30 \mathrm{~cm}_{\text {TRUE }}$ & 0.214 & 0.106 & 2.011 & 0.044 \\
\hline Site fertility ${ }_{\text {Fertile }}$ & -0.425 & 0.092 & -4.611 & $<0.001$ \\
\hline Temperature sum & 0.096 & 0.025 & 3.843 & $<0.001$ \\
\hline Damage density $2-3$ & 1.104 & 0.088 & 12.498 & $<0.001$ \\
\hline Damage density $>3_{3}$ & 1.898 & 0.111 & 17.137 & $<0.001$ \\
\hline Species $_{\text {Spruce }}: \log ($ Height $)$ & 1.634 & 0.358 & 4.561 & $<0.001$ \\
\hline Species $_{\text {Other }}: \log ($ Height $)$ & 1.625 & 0.742 & 2.190 & 0.029 \\
\hline
\end{tabular}


935 Figures

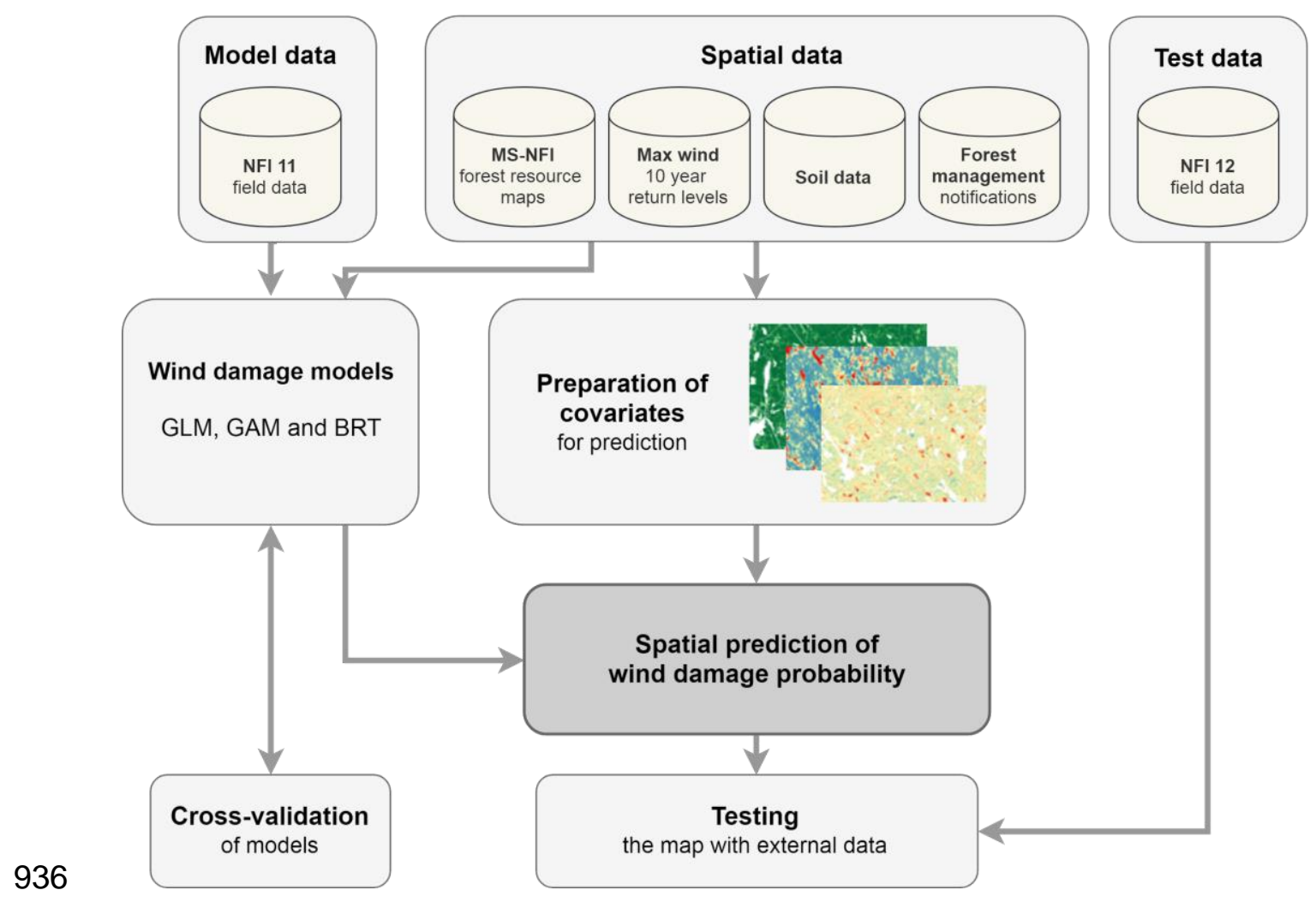

937 Figure 1. General approach and workflow. Abbreviations in the figure: NFI - national forest

938 inventory, MS-NFI - multi-source national forest inventory, GLM - generalized linear model,

939 GAM - generalized additive model, BRT - boosted regression trees 

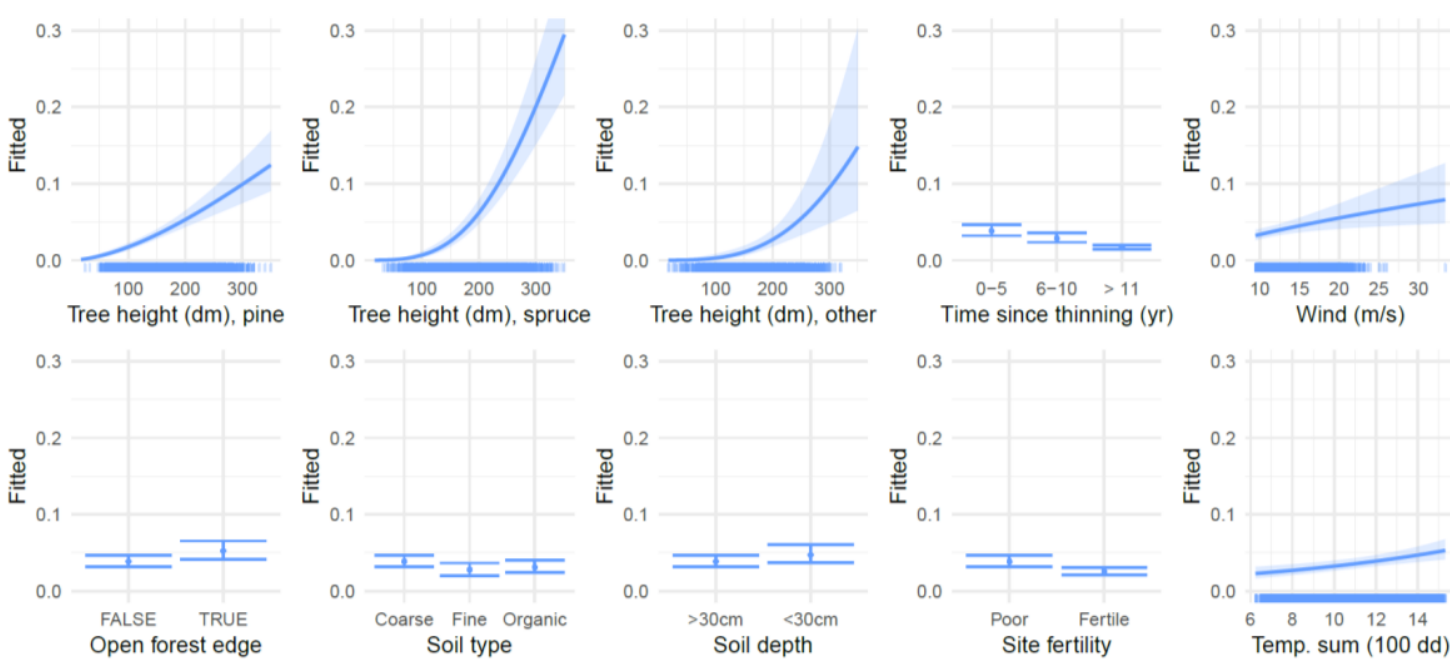

942 Figure 2. GLM partial dependence plots for the map predictors. Prediction of damage 943 probability is calculated for the range of each predictor variable when other predictors are set 944 to average (continuous variables) or reference class (categorical variables). Rugged x-axis 945 describes the distribution of data. Confidence intervals are calculated as $2 \times$ prediction standard error (in the scale of the linear predictor).
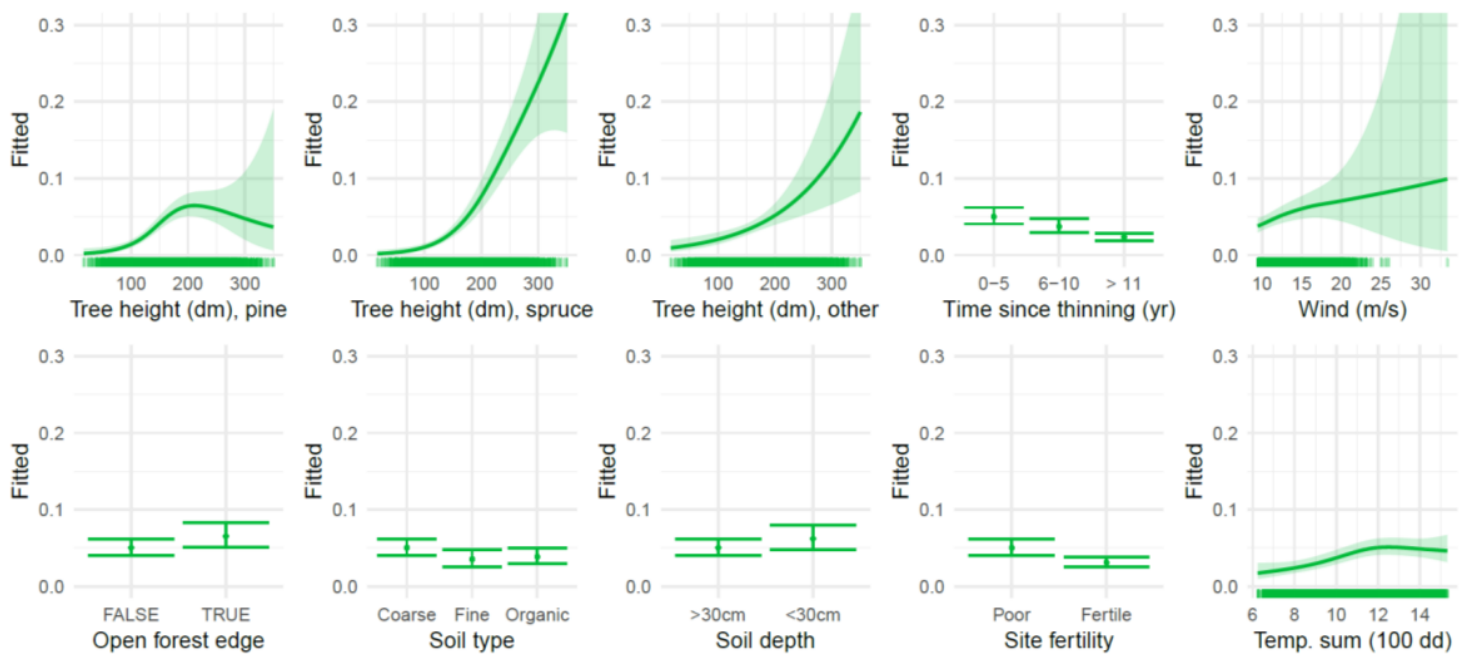

948 Figure 3. GAM partial dependence plots for the map predictors. Prediction of damage 949 probability is calculated for the range of each predictor variable when other predictors are set to average (continuous variables) or reference class (categorical variables). Rugged x-axis describes the distribution of data. Confidence intervals are calculated as $2 \times$ prediction standard error (in the scale of the linear predictor). 

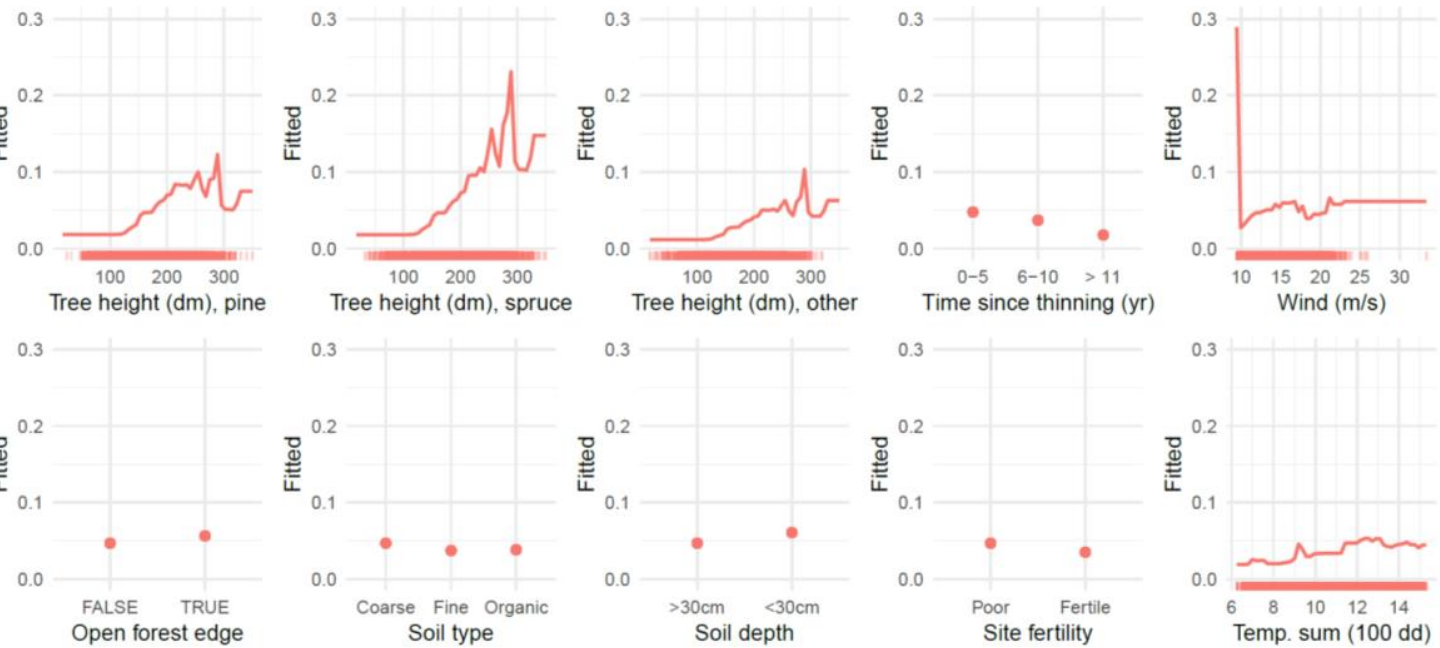

954 Figure 4. BRT partial dependence plots for the map predictors. Prediction of damage 955 probability is calculated for the range of each predictor variable when other predictors are set to average (continuous variables) or reference class (categorical variables). Rugged $\mathrm{x}$-axis describes the distribution of data.
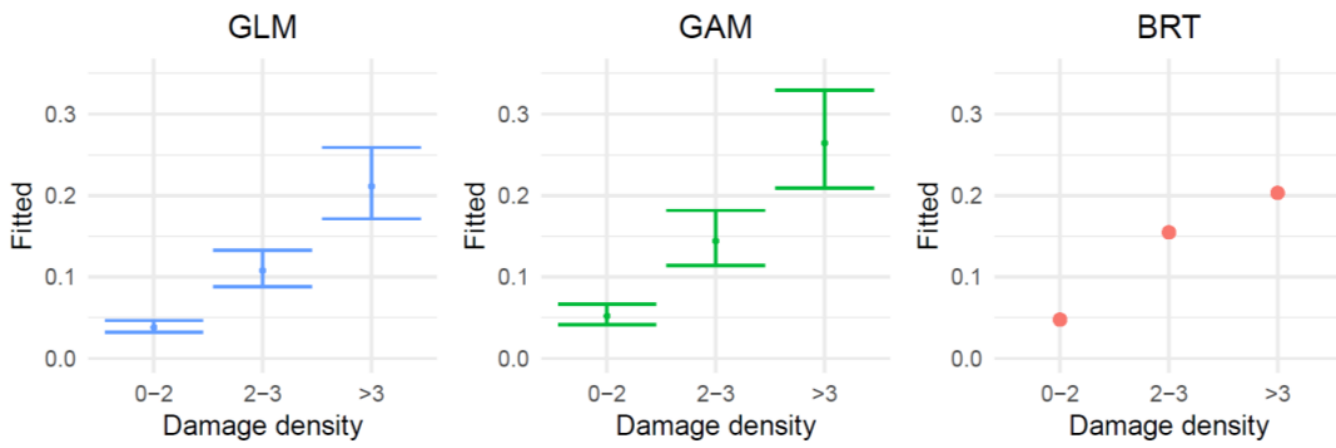

958

959 Figure 5. Partial dependence plots for damage density in the different models (GLM, GAM 960 and BRT). Damage density was included in the models to account for spatial variation in severity of storm damage in the data, and it was set to 0 when calculating the wind damage probability map. Note that the $y$-axis range differs from figures $2-4$. 


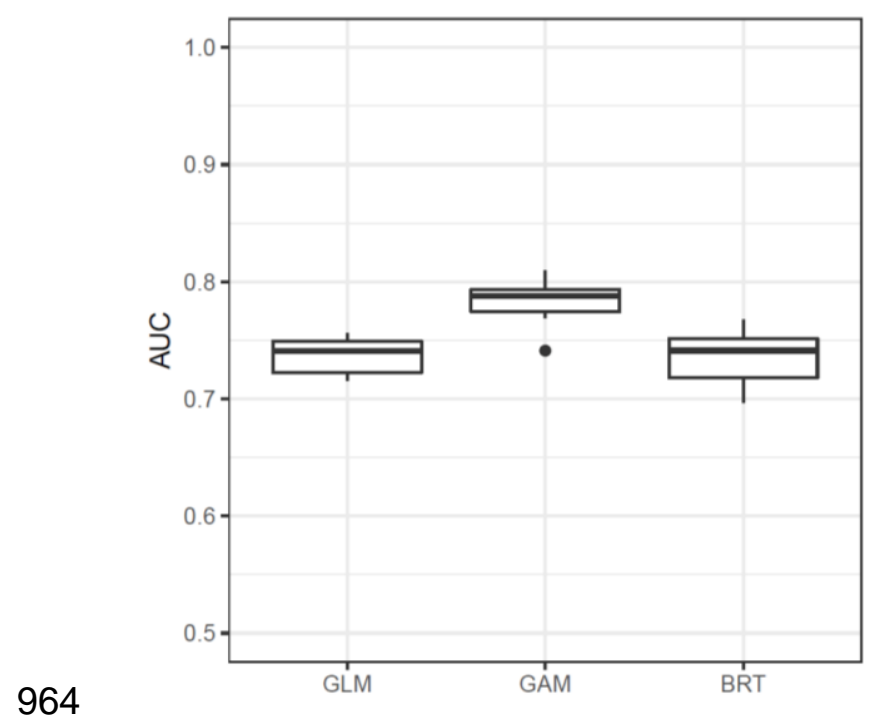

965 Figure 6. Distribution of AUC values in the 10-fold cross-validation for GLM, GAM and BRT.
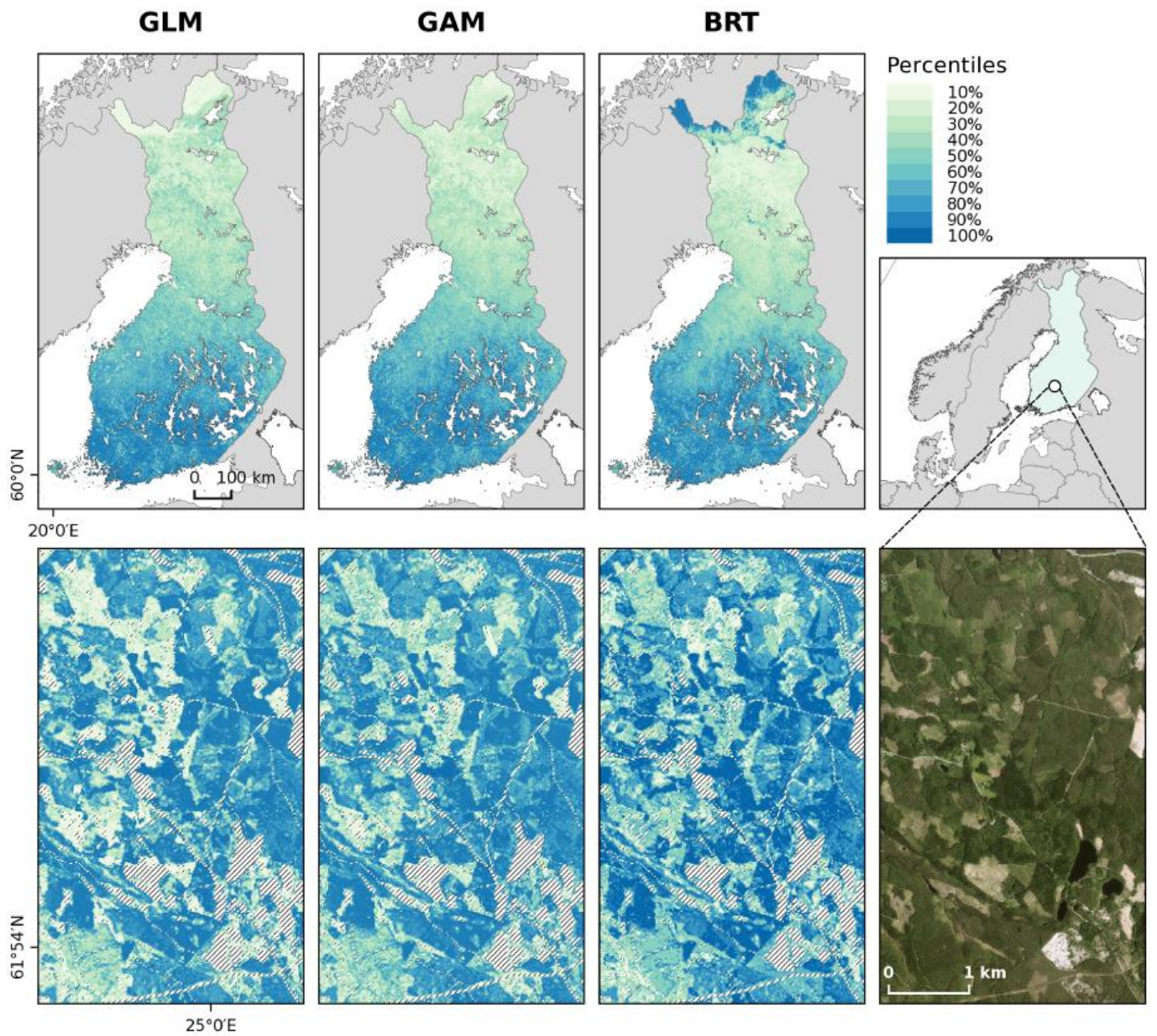

Figure 7. Damage vulnerability maps calculated for the whole country (upper panel) and a

968 fine-scale detail of the maps (lower panel), calculated with the three different damage 
969 probability models (GLM, GAM and BRT), and an orthophoto from the same location (B).

970 Colors in the damage vulnerability map are defined by the percentiles of the map data (e.g.,

971 the first class contain the lowest $10 \%$ of map values). The upper panel maps are resampled

972 to $1 \mathrm{~km} \times 1 \mathrm{~km}$ resolution with bilinear interpolation. Note that the orthophoto is not from the 973 exact same time as the forest resource data used for the calculation of the map. Orthophoto

974 (C) National Land Survey of Finland, published under CC-BY 4.0 licence.
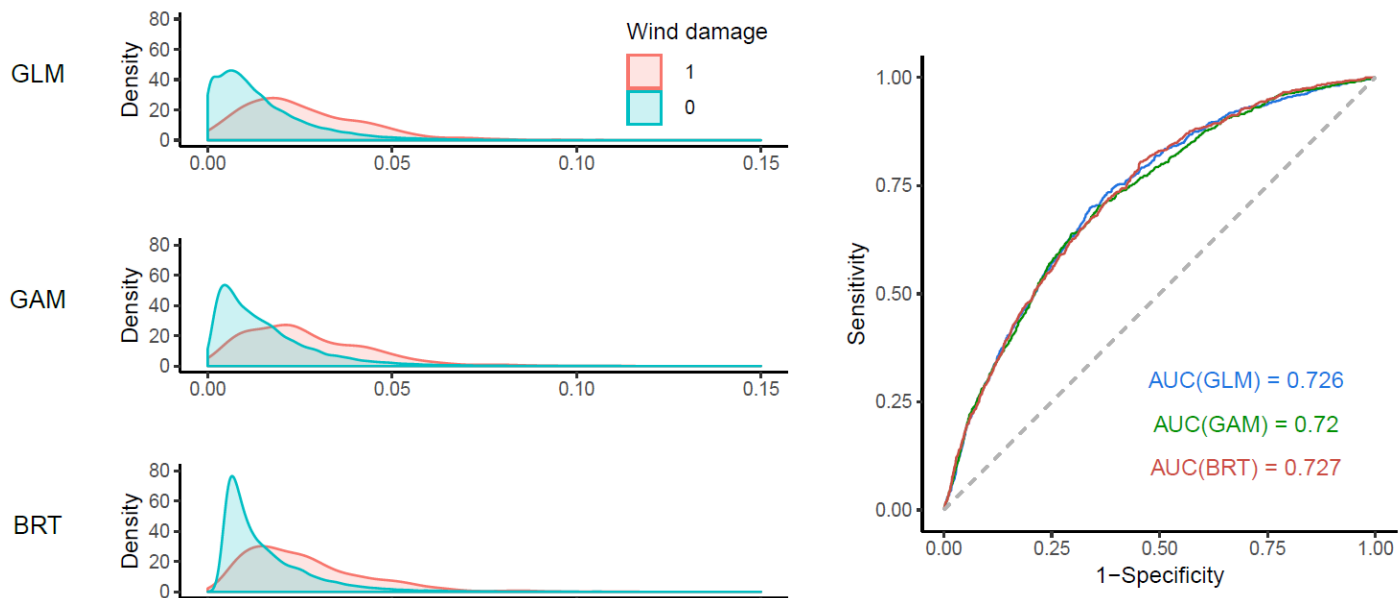

975

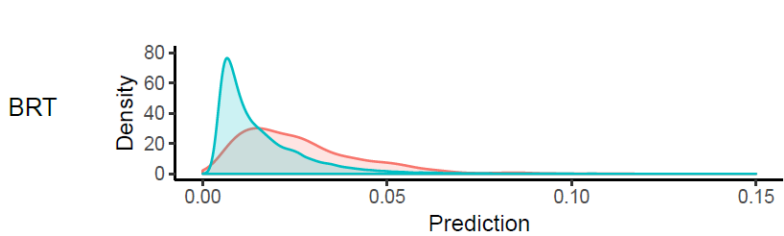

$\mathrm{AUC}(\mathrm{GAM})=0.72$

$\operatorname{AUC}(B R T)=0.727$

976 Figure 8. Density plots of the distributions of map predictions for test data plots with wind

977 damage (red) and without wind damage (blue), and ROC curve showing the ability of the maps to distinguish between damaged and non-damaged test plots for the different model methods (GLM, GAM and BRT). 


\section{Supplementary materials}

981 S1. The damage density ratio variable

982 S2. GAM model results

983 S3. BRT parameter tuning

984 S4. GLM variance-covariance matrix

985 S5. Maps of the model, test and predictor data sets 